\title{
Reseña bibliográfica de: Rodríguez Fraile, L. (2017). Una breve historia del exilio extremeño: deportación y desarraigo migratorio. Hervás (Cáceres): Ediciones del Ambroz. 182 pp.
}

Palabras clave: Exilio - Deportación - Emigración - Extremadura - Nazismo - Franquismo

Keywords: Exile - Deportation - Emigration - Extremadura - Nazism Franquismo

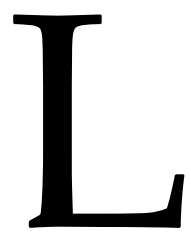

ibro a modo de estudio que sin perder de vista las estadísticas y los datos cuantitativos, va más a lo personal, a mostrar los motivos del exilio, en dar a conocer las diferentes vivencias con entrevistas y testimonios. El objetivo que se marca la autora es el análisis concreto de los exiliados de procedencia extremeña, análisis que hasta ahora no se había intentado de una manera global, sino vinculado a municipios o a exiliados concretos, normalmente personas conocidas.

El pueblo extremeño tradicionalmente es un pueblo de emigrantes a lo largo de los siglos, pero este libro se centra no en las migraciones voluntarias de búsqueda de oportunidades y de empleo, sino del momento concreto de la migración con motivo del exilio, sobre todo en los primeros años del franquismo. La motivación central de los individuos, familias o colectivos es escapar de la represión.

Entre las fuentes documentales se encuentran los mejores especialistas de la actualidad, y la autora también se ha sumergido en diferentes archivos, como el Centro Documental de la Memoria Histórica (CDHM), la documentación de la disuelta Federación Española de Deportados e Internos Políticos (FEDIP), entre otros. Pero también ha recurrido a webs que se mantienen muy actualizadas, como la web deportados.es, formato que permite la ágil incorporación de artículos, fotografías y diferentes documentos. En varias ocasiones la autora pone en valor las últimas investigaciones que se han afrontado sobre extremeños deportados en los campos de concentración del Reich o en los gulag de la URSS. También recoge las últimas aportaciones de documentos de familiares, muchos de los cuales sin el formato web no saldrían a la luz o sería más difícil de acceder a los mismos. Todo ello requiere mucho tiempo de lectura y dedicación.

El libro explica de manera general las razones, la evolución y las consecuencias del propio exilio y, a la vez, presenta ante nosotros los testimonios de extremeños, ya sean

Anuario de la Escuela de Historia Virtual - Año 11 - No 17 - 2020: pp. 170-174. ISSN: 1853-7049. http://revistas.unc.edu.ar/index.php/anuariohistoria 
conocidos, como Arturo Barea o Valentín González, ya sean menos conocidos, como Servideo García.

La autora elimina un vacío sobre el exilio y deportación de extremeños, a la vez que señala diferentes líneas que se deberían investigar en el futuro, como el caso de los españoles prisioneros de los gulags, que son muy difíciles de documentar y requieren un gran esfuerzo.

Comienza analizando las circunstancias de la Guerra Civil en Extremadura, en la que el rápido avance de los nacionales por el territorio provoca que ya a finales de 1936 se pueda dar por finalizada la guerra en tierras extremeñas, con la excepción de grupos guerrilleros o "bolsas". Ante esta situación muchos extremeños optaron por escapar y alistarse en el ejército de la República, pero territorialmente fuera ya de Extremadura. La mayor parte de los extremeños exiliados y sus familias son de este grupo, ya que la huida normalmente solo pudo ser a territorio de la República y de forma muy excepcional a Portugal, por encontrarse este país inmerso en la dictadura de Salazar, régimen aliado de Franco.

Desde un primer momento, ya sea por afinidad política, ya sea por las facilidades de idioma aparece como destino preferente Hispanoamérica, de manera especial Argentina y México. Por motivos más políticos la URSS, y también Francia, en este caso por razones fronterizas y además de dinámica histórica, ya que el territorio francés está muy familiarizado con la llegada de migraciones y de exiliados españoles. Ya en el siglo XIX con la propia Guerra de la Independencia y en las guerras carlistas, fueron muchos los españoles, entre ellos extremeños, que llegaron a Francia, unas veces de manera voluntaria y otras veces forzada. Un ejemplo es el valido Godoy. El ámbito de estudio del libro se refiere al exilio y a las migraciones forzadas, que tuvieron lugar en los primeros años del franquismo. No recoge el hecho de que en los años veinte y treinta hubo españoles que emigraron a Francia por razones laborales, ya que en ese caso no son exiliados.

El exilio en Francia vinculado con la Guerra Civil y represión franquista será trágico, pues tuvo como consecuencia que muchos extremeños fuesen deportados a los campos de concentración del nazismo. En esta parte del libro el referente bibliográfico de la autora es la profesora de la UNED y especialista en exilios y migraciones Alicia Alted. Desde este momento, la autora empieza a introducir testimonios personales y familiares de los extremeños para explicar las vivencias y circunstancias, como sucederá en el siguiente punto, que es el de la deportación. Explica bien el contexto internacional y el desarrollo de acontecimientos, y cómo todos ellos afectaron a los extremeños. En el momento del paso a Francia de estos, siendo la mayoría combatientes, explica las difíciles circunstancias en las que quedan sus familias y en concreto sus mujeres, con dificultad para huir, pasando por prisiones y el retorno muchas veces de ellas al pueblo con castigos y humillaciones públicas. La autora tampoco pierde pista a lo cambiante de la actitud hacia los exiliados de las autoridades francesas, que en un primer momento apuestan por demonizar a los exiliados. 
Todo ello abre una brecha familiar de años hasta que los exiliados recuperen a sus familiares; otras veces el encuentro no se producirá ya, siguiendo sus vidas por separado. Unas veces se intentarán reencontrar en el territorio del exilio y otras veces introduciendo información o cartas en España para hacérsela llegar a sus familiares, cosa que no será precisamente fácil. La propia recepción de los documentos generados por el gobierno francés de fallecidos en los campos de concentración del Reich para solicitar indemnizaciones muchas veces no llegó a los familiares destinatarios en España, tanto que en muchas ocasiones los familiares no sabrán si alguien ha fallecido prácticamente hasta los años 80.

La autora explica con detalle la situación de los campos de refugiados del sur de Francia, la separación de hombres que permanecen en esos campos, y las mujeres y niños que son repartidos por toda Francia. También explica cómo algunos consiguen en ese momento llegar a Sudamérica o a la URSS. Gran parte de los que permanecen en los campos de refugiados del sur de Francia entran a formar parte de las Compañías de Trabajadores Extranjeros (CTE), destinados a reforzar las tropas francesas contra el ataque potencial de los alemanes. Así, unos trabajan en la línea de frontera preparando las defensas y otros en bases navales y cuarteles. Son los de la frontera los que en 1940 se ven sorprendidos por el ataque alemán y son capturados. Francia se rinde y los españoles quedan abandonados a su suerte, unos capturados y otros escapando como fugitivos. En esta parte y en la de la deportación, la autora usa el interesante relato de uno de aquellos españoles, Servideo García.

Desde ese momento, el libro se centra en los campos de concentración del Reich Nazi, el mundo de la deportación, con su día a día, los trabajos forzados, el aniquilamiento sistemático, los intentos de evasión, todo ello refiriéndose de manera concreta con ejemplos de extremeños. Desde ese momento, la autora comienza a usar tablas de diseño propio que resultan muy interesantes para seguir el relato y las explicaciones. Para ello usa los datos del "Memorial" de Bermejo y Checa, inventario de españoles prisioneros en los campos de concentración realizado en 2006, que en aquel momento identificó a unos 300 extremeños prisioneros de los stalag y campos de concentración, si bien ese dato a día de hoy se debe revisar, ya que desde la elaboración del citado "Memorial", se ha ampliado de manera significativa el número de deportados conocidos.

La autora se centra en los españoles deportados en 1940-1941, en su mayoría con destino a Mauthausen, los prisioneros de "triángulo azul", identificados como apátridas y la $S$ de españoles; en una tabla explica el significado de los distintivos de colores de los diferentes presos del sistema Nazi. Ahora bien, aunque sean muchos menos porcentualmente, también hubiese sido interesante que explicase con mayor profundidad las deportaciones de 1944-1945, que son mayoritariamente resistentes, hombres y mujeres, escapados de los campos de refugiados del sur de Francia, núcleos que formaron la guerrilla o maquis, y que están ya coordinados con las fuerzas de Resistencia francesas, enfrentándose a los Nazis en la Francia ocupada y a la Milicia en 
el gobierno filonazi de Vichy. Un estudio de estos deportados de 1944-1945 puede arrojar datos novedosos, como la existencia de mujeres extremeñas en la Resistencia y posiblemente prisioneras en los campos de concentración de Alemania; ahora bien, no es sencillo de estudiar y analizar. Esos prisioneros de 1944-1945 además cambian de distintivo en el régimen de los campos de concentración, ya que tienen el "triángulo rojo" de prisioneros políticos con SP de españoles, ya no considerados apátridas como tal.

En la cuestión de los campos de concentración, uno de los ejes del libro, la autora usa como referente el mencionado "Memorial", así como documentos y libros de Carlos Hernández de Miguel, Montserral Llor y David Wingeate, de la Amical de Mauthausen española, y de la web deportados. Explica bien la vida y la muerte en los campos de concentración, y aporta un gráfico muy interesante haciendo seguimiento de extremeños fallecidos, supervivientes o en paradero desconocido. Llega a hacer nuevos gráficos separando por provincias (Cáceres y Badajoz), por municipios y también por campos, sacando el porcentaje en el cual mayoritariamente van a parar a Mauthausen, pero también a Dachau, entre otros. A la vez, la autora se apoya en el relato de Servidio para explicarnos bien la deportación.

$\mathrm{Al}$ respecto de la deportación, la autora pone en valor las últimas investigaciones sobre extremeños, la de Isidro Sánchez y de Tomás Iglesias, la del primero realizada por su sobrino-nieto y profesor en la UNED, Juan P. Rodríguez, y la segunda por los familiares Ana Vidal Iglesias y Daniel Moreno. La propia autora del libro también ha hecho aportaciones en los últimos años, en concreto sobre el deportado Cirilo Moreno.

Es interesante la tabla de prisioneros extremeños en Hartheim, dado lo dramático del desenlace generalizado de los prisioneros que allí terminaron, que fueron víctimas de crueles experimentos médicos.

En las siguientes páginas, la autora pasa a explicar el tema de las solicitudes de indemnizaciones y pensiones de los deportados una vez liberados. Esas solicitudes, que se encuentran en Vincennes o Caen, son una gran fuente de información para posibles ampliaciones del libro y posteriores estudios, ya que junto a la documentación e información más completa que aportan, pueden tener documentos personales, diplomas, y corregir posibles datos erróneos. La autora, en este tema de pensiones, recoge varias cartas de solicitudes, documentación que no es sencilla de conseguir. Desde ese momento también se abre una nueva fase de migraciones, siendo las minoritarias las de retorno a España por temor a represalias. Mayoritarios son los casos de migraciones a Hispanoamérica o de permanencia en territorio francés, intentando en ambos casos la reagrupación familiar en territorio extranjero, cosa que se tardó años en conseguir. En todo ello, la autora, junto a la mencionada profesora Alted, usa nuevas fuentes, como el portal de Migraciones Iberoamericanas. Con todo ello realiza una tabla con las profesiones ejercidas por los extremeños en el exilio, en su mayoría agricultores, aunque extremeños hubo de todas las profesiones y condiciones sociales. En este punto señala que uno de los propios extremeños fue presidente de la República 
en el exilio, el madroñero Fernando Valera. También explica la procedencia de diferentes partidos y sindicatos de los exiliados extremeños; en alguna ocasión son militares o personas sin filiación política.

De manera concreta y en un capítulo completo la autora analiza el exilio y deportación a la URSS. La fuente bibliográfica principal es la profesora de la UNED Luiza Iordache y el propio testimonio del extremeño Valentín González "el campesino", uno de los más importantes comandantes del ejército de la República. A través de su testimonio la autora explica las desconfianzas de los soviéticos hacia los españoles, el régimen totalitario de la URSS y cómo muchos de los españoles republicanos españoles fueron a parar a los "gulag" con el régimen de trabajos forzados, compartiendo destino con miembros de la División Azul, contingente de voluntarios franquistas de refuerzo al ejército del Reich alemán. La autora explica las similitudes y diferencias entre el régimen de campos nazis y el soviético. En una tabla realizada sobre la documentación de Iordache aporta los nombres de los extremeños republicanos prisioneros en la Unión Soviética, si bien reconoce la dificultad de poder investigar este tema. Para aquellas personas el comunismo soviético de Stalin, que había sido un sueño, se convirtió en una pesadilla. La autora nos explica la obsesión por conseguir la repatriación o autorización de salida a otro país de aquellos extremeños. Sobre estas repatriaciones la autora también aporta una tabla con diferentes solicitudes.

En la parte final del libro aporta una bibliografía sobre todos los contenidos tratados muy actualizada, incluyendo webgrafía y documentales, así como una serie de anexos con documentos, fotografías y más tablas con información.

El balance del libro resulta positivo, sobre la base de un proceso bibliográfico y de documentación muy cuidado y con los últimos datos e investigaciones. Abre líneas de investigación que ella misma en un futuro podría desarrollar, como los extremeños deportados en los años 1944-1945 en la Alemania Nazi o prisioneros de los gulags de la URSS con el stalinismo.

Juan Pedro Rodríguez Hernández Profesor-tutor Universidad Nacional de Educación a Distancia Miembro de la Federación Francesa de Deportados jprodriguez@madridsur.uned.es

Para citar esta reseña:

Rodríguez Hernández, Juan Pedro (2020): Reseña bibliográfica de: “Rodríguez Fraile, L. (2017). Una breve historia del exilio extremeño: deportación y desarraigo migratorio. Hervás (Cáceres): Ediciones del Ambroz. 182 pp." Anuario de la Escuela de Historia Virtual 17, 170-174. 